\title{
Debate: La Educación Sexual Integral, ¿es feminista? Presentación
}

\section{- Catalina González del Cerro ${ }^{12}$}

Corría el año 2016, y una consigna brotó, como tantas otras, en la tierra siempre fértil de la creatividad feminista: "Para decir 'Ni una menos' hay que defender la Educación Sexual Integral"13. Para entonces dos tendencias se habían tornado evidentes en la Argentina. Por un lado, la certeza de que el nuevo gobierno de la Alianza Cambiemos estaba decidido a eliminar o reducir a su mínima expresión los diversos programas estatales en el marco de un modelo de desfinanciamiento y estigmatización de la escuela pública. Por otro lado, este contexto de ajuste -que llevó rápidamente a una precarización de la vida de muchxs y sobre todo de muchas- convivía con los gritos cotidianos de un actor político para varixs impensado: la marea feminista. Caldeado durante décadas de organización y Encuentros Nacionales de Mujeres, y catapultado a la opinión pública tras la masiva movilización "Ni una menos" del 2015, este movimiento también parece estar decidido a exigirle a la sociedad un cambio de rumbo. Las políticas públicas que son parte de la "agenda de género" aparecieron, así, tambaleando en este cruce perpendicular de maremotos. ¿Por qué la Educación Sexual Integral (ESI) es algo que las feministas debamos defender? ¿Puede una política educativa ser feminista? ¿Puede la escuela, santuario de la modernidad patriarcal, ser feminista?

Corre el año 2018. Las reflexiones que presentamos en esta edición de Debates fueron escritas en un momento -otro más- de grandes conmociones colectivas. Una enredadera de pañuelos verdes está trepando por los muros del Congreso y también, de las aulas: la sociedad entera está discutiendo sobre la legalización del aborto con una intensidad inédita. De ambos lados de la Avenida Entre Ríos, todxs parecen defender, ahora sí, la educación sexual para decidir. Incluso quienes históricamente se han opuesto a ella, como la jerarquía de la Iglesia Católica. ${ }^{3}$ También lxs voceros de este mismo gobierno que se ocupó de desfinanciarla. ${ }^{4}$ Estos sectores oportunistas posiblemente se están haciendo, temerosos, la misma pregunta: ¿la Educación Sexual Integral que tenemos desde el 2006... es feminista?

Sin pretender dar una respuesta cerrada, este interrogante fue elegido para provocar un encuentro de diversas voces con el fin de actualizar la reflexión sobre dónde estamos situadxs hoy. Partimos de observar que en los últimos años hubo un interés renovado y una puesta en agenda de la implementación de la ESI de la mano de otros o nuevos actores, como es el caso de lxs jóvenes estudiantes. Para este Debate se invitó a participar a personas que de distintas formas han sido "testigas" activas de los derroteros de la ESI, en su calidad de docentes, investigadoras y activistas, combinación de identidades que por cierto (y no casualmente) es usual encontrar en este campo que cruza la educación con el género y las sexualidades.
1. Doctora en Ciencias de la Educación y Profesora de Ciencias Antropológicas (FFyL/UBA). Investigadora y becaria posdoctoral (IICE/CONICET), su tesis se titula "Educación Sexual Integral, participación política y socialidad online: Una etnografía sobre la transversalización de la perspectiva de género en una escuela secundaria de la Ciudad Autónoma de Buenos Aires". Integrante del equipo Mariposas Mirabal UBA y del Frente popular por la ESI - CABA. 2. Este lema tomó masividad a partir de un comunicado lanzado en septiembre de 2016 frente a intentos de despidos en el Programa Nacional ESI y que dio origen al Frente por la ESI https://goo.gl/7rcXVV

\author{
3. Comunicado del Episcopado \\ Argentino 23/2/2018 http://www. \\ episcopado.org/contenidos. \\ php?id=1650\&tipo=unica \\ 4. Informe del Observatorio de \\ Derechos Humanos de la CABA \\ 4/12/2017 https://odhbsas.wordpress. \\ com/category/educacion/
}


5. Retomo aquí el nombre del dispositivo elaborado por el Programa Nacional ESI para abordar en las instancias de formación a docentes que remite a los modos pos los que ingresa la ESI a la escuela.
La intuición que guió esta convocatoria se desprende de una lectura de que, por un lado, la ESI sigue siendo una conquista del movimiento feminista que requiere de su monitoreo constante, y por otro lado, que la traducción escolar de esta ley se presenta como una renovada "puerta de entrada" para pensar las formas en que el/los feminismos argentinos están interpelando a los modos tradicionales de hacer, sentir y pensar la política, más acá y más allá del Estado. Las docentes (y estudiantes) feministas (y defensoras de la ESI) están interpelando, sin pedir permiso, al propio sistema educativo; sistema que como pocos, nos invita a revisar de forma diaria las tensiones entre lo particular y lo universal. Si las escuelas son ámbitos privilegiados para pensar e identificar los climas de época, la ESI -con su escueta ley, su Programa y principalmente con los múltiples sentidos que se diputan en torno a ella- es una política educativa privilegiada a partir de la cual identificar los múltiples trechos del dicho legal al hecho escolar.

Además de la pregunta "disparadora" que titula este debate, las autoras fueron invitadas a reflexionar alrededor de los encuentros y desencuentros entre una política pública -la ESI- y los modos feministas de pensar la política ¿Cómo están interpelando a la política tradicional los estilos, las temporalidades y espacialidades de los feminismos populares que reclaman por su plena implementación? ¿Cómo fue leída y apropiada la ESI desde su gestación hasta la actualidad dentro de los movimientos feministas y de disidencia sexual? ¿Qué aspectos aparecen como defendidos y/o cuestionados por parte del amplio espectro de actores políticos que pugnan por moldearla? ¿Qué está sucediendo, efectivamente, en las escuelas? Las reflexiones que siguen constituyen en conjunto una cartografía de los sujetos y los debates en torno a lo deseable, a lo posible y a lo aún no imaginado de la enseñanza y el aprendizaje acerca de los cuerpos sexuados. Se trata de una serie de contribuciones que ahondan en los múltiples niveles que deben ser tenidos en cuenta para analizar esta -y también otras- políticas públicas en épocas de democracia.

Los primeros tres escritos brindan un panorama amplio de los contextos y sobre todo de los procesos sociales a partir de los cuales la normativa fue haciéndose carne en las escuelas. Para comenzar, el texto de Jésica Báez nos recuerda la importancia de abordar estas preguntas a partir de ampliar el marco al contexto Latinoamericano y en clave histórica. Reconstruye así los desafíos que representó la inclusión de la educación sexual en los distintos países, y para graficarlo trae tres escenas pedagógicas contemporáneas en donde es posible observar los nudos de sentidos que disputan los sectores sociales que pretenden definirla. Eleonor Faur, por su parte, reconstruye el proceso de la institucionalización de la educación sexual en el contexto argentino. Lo hace, también, a partir de distintas escenas, o mejor dicho momentos y escenarios -la Catedral, el Palacio, las aulas y la calle- para argumentar que la ESI es una política determinada por "estructura de arenas", en la cual la Iglesia Católica jugó un rol central por tratarse de la única institución que educaba en sexualidad de modo sistemático desde antes de que existiera la ley. Desde un enfoque más etnográfico, el recorrido que trae Luciana Lavigne deja ver los derroteros que vivió la normativa en la Ciudad Autónoma de Buenos Aires, su vinculación con la perspectiva de género, el rol reciente del lenguaje inclusivo y la herencia de los grupos de concienciación feministas en el dispositivo de la "reflexión sobre nosotras/os mismas/os" que invoca el Programa Nacional ESI, entre otros ejes que fueron complejizando esta política en permanente construcción.

Por otra parte, los otros tres trabajos afinan la mirada desde las experiencias de quienes habitan las aulas diariamente, sobre aspectos de este recorrido que ameritan una mayor atención. En ese sentido el escrito de la profesora Verónica Fulco invita a revivir diversos desplazamientos propiciados por la ESI que suponen, dice la autora, un modo de hacer política en la escuela. Allí conviven nuevos perfiles de 
jóvenes estudiantes -que con sus identidades y posiciones a veces dejan en offside incluso a las más feministas de las profesoras- con los perfiles sumamente heterogéneos de docentes, algo que requiere una revisión profunda de los criterios de idoneidad necesarios para enseñar sexualidad en la actualidad. Quien retoma esta pregunta sobre cómo se enseña ESI es val flores, que se ocupa de trasladar algunos debates que suelen restringirse a los ámbitos feministas -en particular, sobre las posiciones prosexo -hacia el sistema educativo; ámbito en el que predominan los imperativos morales y la asepsia sexual como requisito del régimen de producción de conocimientos. Sin dejar de pensar la ESI como artefacto crítico para una política sexual feminista, esta maestra escritora activista busca con el escrito "incidir en el montaje colectivo de una urgente imaginación pedagógica que haga del derecho al gemido una demanda prioritaria". En esta línea de revisar las deudas de la ESI, Alba Rueda elabora un minucioso análisis de los textos y documentos de la normativa para cuestionar los modos en que se presenta a la diversidad sexual y argumenta que los saberes de los movimientos trans no fueron debidamente oídos ni plasmados. Sin embargo dice, es posible entablar en este contexto intersticios potentes, y poner en valor las estrategias que muchas docentes vienen realizando para incluir otras voces.

Como horizonte deseable de todo debate, lo que pretendemos con este compilado de ideas y emociones es sembrar nuevas preguntas para propiciar futuros encuentros. ¿Cómo interrogar esta época de precipitaciones sin dejar de recuperar lo acumulado en diversas batallas? ¿Cómo construir esta urgente imaginación pedagógica que propone val flores, dentro y fuera de los muros de las aulas? 
